\title{
Estrogen receptor, progesterone receptor, and bcl-2 are markers with prognostic significance in CIN III
}

\author{
J. A. FONSECA-MOUTINHO*, E. CRUZt, L. CARVALHO $\ddagger$ H. J. M. PRAZERES§, M. M. P. DE \\ LACERDAt, D. P. DA SILVA*, F. MOTA $₫$ \& C. F. DE OLIVEIRA $\uparrow$ \\ *Department of Gynecology; †Department of Pathology, Portuguese Cancer Institute; $\ddagger$ Department of Pathology, Medicine \\ School of Coimbra; Coimbra University Hospital; §Portuguese Cancer Institute; and 9 Department of Gynecology, \\ Medicine School of Coimbra, Coimbra University Hospital, Coimbra, Portugal
}

\begin{abstract}
Fonseca-Moutinho JA, Cruz E, Carvalho L, Prazeres HJM, de Lacerda MMP, da Silva DP, Mota F, de Oliveira CF. Estrogen receptor, progesterone receptor, and bcl-2 are markers with prognostic significance in CIN III. Int J Gynecol Cancer 2004;14:911-920.
\end{abstract}

There are no known biological markers or technologies to predict the natural history of an individual CIN III. The probability of progression is considered greater with the persistence of high-risk human papillomavirus (HPV) infection and age. p53 polymorphism has been associated with cervical carcinogenesis. Hormone-induced cervical cancer is mediated by estrogen receptor (ER) and progesterone receptor (PR). In cervical cancer, increased bcl-2 and Bax immunoreactivity is generally associated with a better prognosis. The purpose of this study was to evaluate the value of HPV 16 and HPV 18 typing and p53 codon polymorphism genotyping by polymerase chain reaction and ER, PR, bcl-2, and Bax expression by immunohistochemistry in predicting the CIN III clinical behavior of CIN III lesions. We studied the expression of these prognostic factors in the CIN III adjacent to squamous cell microinvasive carcinomas of the cervix (MIC) from 29 patients with FIGO stage IA1 cervical cancer and in 25 patients with CIN III and no documented focus of invasion. In the MIC group, only the CIN III was considered at least $2 \mathrm{~mm}$ away from the microinvasive complex. The ER, PR, bcl-2, and Bax immunoreactivity was scored as positive ( $>10 \%$ staining cells) and negative $(<10 \%$ staining cells). No significant difference was observed between MIC and CIN III group concerning HPV infection and p53 polymorphism. The ER, PR, bcl-2, and Bax immunohistochemical expression was stronger and more frequent in the CIN III group. After multivariable analysis, coexpression of ER, PR, and bcl-2 was the only independent factor in defining low risk of progression for CIN III. Our study suggests that coexpression of ER, PR, and bcl-2 may be a useful tool in identifying the CIN III lesions with low risk of progression to cervical cancer.

KEYWORDS: cervical microinvasive carcinoma, CIN III, immunohistochemistry, prognosis.

Address correspondence and reprint requests to: José Alberto Fonseca-Moutinho, Centro Médico Serpa Pinto, R. Carlos Maria Pereira, 5B Cav. Dta, 2300-457 Tomar, Portugal. Email: jafmoutinho@mail.telepac.pt
Cervical cancer is one of the most frequent cancers in women, with an estimated worldwide incidence of about 371,000 new cases per year and an overall 5 -year survival ranging from 44 to $66 \%$ for all clinical stages $^{(1)}$. 
Invasive cancers are usually accompanied by CIN III, and presumably this lesion precedes most carcinomas $^{(2)}$. The rate of CIN III progression is unknown, but based on follow-up studies of untreated or incompletely treated CIN III, one may assume that risk for cancer progression may be as low as $20 \%$ to up to $70 \%$, and regression rate may be as high as $32 \%^{(3,4)}$. To prevent invasive cervical cancer, a successful treatment of high-grade CIN, particularly CIN III, is the gold standard management ${ }^{(5)}$. The surveillance schedule for treated patients is not so well defined. Identifying a subset of patients with CIN III with low risk for cancer progression may be helpful in clinical practice for rationalizing follow-up.

HPV infection is present in virtually all cancers and is the strongest epidemiological factor for cervical cancer development ${ }^{(6)}$. Among women with cervical cancer, HPV 16 is the most prevalent HPV type. When determined by polymerase chain reaction (PCR), HPV 16 genoma accounts for more that half of the cases of CIN III and invasive cervical cancer with variations according to race and country ${ }^{(6-11)}$.

Viral integration is important for cell transformation and cervical carcinogenesis. In invasive carcinomas of the cervix, the genoma of HPV 16 and HPV 18 is integrated in up to $70 \%$ of the cases ${ }^{(12,13)}$. When viral integration occurs, the HPV genome breaks in the E2 region resulting in loss of its suppressive function on E6 and E7. The E6 gene product of high-risk HPV binds with high affinity to p53, inactivating it by inducing degradation through a selective ubiquitindependent proteolytic pathway, promoting uncontrolled cell proliferation and eventual development of cervical neoplasia ${ }^{(14,15)}$. Somatic and germ line mutations of p53 are rarely detected in cervical cancers $^{(16,17)}$; however, at least 10 p53 polymorphisms have been described in both coding and no-coding regions of the gene ${ }^{(18)}$. Storey et al. ${ }^{(19)}$ were the first to show that the risk for the development of HPVassociated cervical cancer in white British women was significantly higher for arginine homozygosity (Arg/ Arg) at codon 72 in the p53 amino acid sequence than for arginine heterozygosity (Arg/Pro) and proline homozygosity. Some studies are in agreement and others have refuted these observations, and these conflicting results have been attributed to ethnic differences in allelic frequencies, sample size, selection bias of controls, DNA source, and the methodology used $^{(20,21)}$.

The HPV E7 protein binds to the Rb-E2F complexes, releasing $\mathrm{E} 2 \mathrm{~F}$ protein, and targets $\mathrm{Rb}$ protein for ubiquitin-dependent proteolysis ${ }^{(22)}$. E2F-1, the best-characterized member of the E2F family, acti- vates the transcription of genes for S-phase and induces apoptosis in the presence of functional p53 protein $^{(23,24)}$. Thus, during HPV infection, the proapoptotic signals generated by E7 may be totally or partially counterbalanced by E6 protein.

The product of the proto-oncogene bcl-2 may block apoptosis. Overexpression of bcl-2 is generally associated with a better prognosis in several malignancies including cervical cancer ${ }^{(25-29)}$, and increased Bax immunoreactivity was described as a favorable prognostic factor in cervical cancer ${ }^{(30-33)}$.

An imbalance between HPV-induced cell proliferation and apoptosis may be not sufficient for the development of invasive cervical cancer, and several possible cofactors have been identified, including the steroid hormones estrogen and progesterone. Most cervical cancers arise in the transformation zone, an area known as the most estrogen- and progesteronesensitive region of the cervix ${ }^{(34)}$. Expression of estrogen receptors (ERs) and progesterone receptors (PRs) has been reported to be a favorable prognostic factor in breast cancer ${ }^{(35)}$, endometrial carcinoma ${ }^{(36)}$, ovarian cancer $^{(37,38)}$, and cervical adenocarcinoma ${ }^{(38)}$. In squamous cell carcinoma of the cervix, ER and PR expression had minor prognostic value ${ }^{(39)}$, but via their receptors, estrogen and progesterone are involved in cervical carcinogenesis ${ }^{(40)}$ by increasing the genoma expression of HPV 16 and HPV $18^{(41-43)}$.

The purpose of this study was to evaluate the value of HPV 16 and HPV 18 typing, p53 codon polymorphism genotyping, and ER, PR, bcl-2, and Bax immunohistochemical expression as prognostic factors in CIN III.

\section{Patients and methods}

\section{Patient characteristics}

For this study, two groups of material were selected (i) MIC group - the CIN III of 30 patients with the diagnosis of FIGO stage IA1 squamous cell carcinoma of the cervix (MIC) diagnosed between 1996 and 1999; (ii) CIN III group - the CIN III from the 30 first cases with diagnosis of CIN III, with no documented invasive focus, diagnosed by cone biopsy in 1998 were also retrieved for comparative analysis. All cases were diagnosed, treated, and were followed up at the Gynecology Department of Portuguese Cancer Institute of Coimbra. All patients had documented HIV seronegativity, were not pregnant, and had no history of drug addiction as well as no immunosuppressive therapy in the last 6 months. 
Two pathologists (LC and EC) reviewed all slides from punch biopsy, conization, and hysterectomy, and the pathological classification was obtained by consensus between them according to the criteria formulated by the World Health Organization. In the MIC group, only the CIN III at least $2 \mathrm{~mm}$ away from the microinvasive complex was studied, and from this group one case was excluded because the material was considered not suitable for immunohistochemistry. From the CIN III group, five cases were excluded: one was lost to follow-up; one due to recurrent CIN III developed 6 months after treatment; one had ASCUS Pap smear at the eighteenth month of follow-up; and two were considered not suitable for immunohistochemistry.

The diagnosis of MIC was obtained by conization in $27(93.1 \%)$ cases and by incidental hysterectomy in two $(6.9 \%)$. In all cases of MIC, the hysterectomy was the definitive treatment, and in the CIN III group, $15(60.0 \%)$ patients were submitted to subsequent hysterectomy and $10(40.0 \%)$ patients remained in follow-up.

All patients selected for this study had a follow-up of at least 30 months, with no documented CIN or invasive recurrence or abnormal Pap smear.

\section{Tissue specimens}

The specimens were formalin fixed and paraffin embedded. From each, we selected the two more representative blocks. For immunohistochemistry, $3-\mu \mathrm{m}$ thick consecutive sections were cut from the respective tumor block.

\section{Detection and typing of HPV}

HPV DNA was extracted according to standard protocols ${ }^{(44)}$. Consensus primers for L1 gene were used as described by Kleter et al. ${ }^{(45)}$. Specific primers for HPV 16 E6 gene were used, as described by Shibata et al. ${ }^{(46)}$ and specific primers for HPV 18 genes were used as initially described by Tam and Chow ${ }^{(47)}$. Agarose gel electrophoresis then confirmed the specificity of the amplified DNA. Controls were always used.

\section{Detection of p53 codon 72 polymorphic genotypes}

Three to six $10-\mu$ thick sections were cut onto histological slides from each case. p53 codon 72 Pro and Arg genotypes were analyzed by allele-specific PCR according to the method described by Storey et al. ${ }^{(19)}$. The PCR products were subjected to electrophoresis on $1 \%$ agarose gel, using $\times 10.04 \mathrm{M}$ tris-acetate-EDTA $(0.001 \mathrm{M})$. Gelstar ${ }^{\circledR}$ Nucleic Acid Gel Stain (BMA) according to the manufacturer's instructions then stained the gel (CARYBREX Bioscience, Rockland, ME).

\section{Bax and bcl-2 immunohistochemistry}

The antigens were incubated with monoclonal mouse antihuman bcl-2 (clone 124 (1/40), isotype IgG1; Dako, Glostrup, Denmark) or polyclonal rabbit antihuman Bax (1/500, Dako). To identify antigenantibody complexes, an immunoperoxidase method employing an avidin-biotin (StreptABC/HRP) peroxidase complex was used for bcl-2 (TechMate 500 Plus, MSIP protocol, Vector Laboratories, Burlingame, CA), and for Bax a catalyzed signal amplification (CSA) system with CSA rabbit link was used. Peroxidase activity was demonstrated by incubating the slides in 3,3'diahinobenzidine (DAB) (Dako) followed by counterstaining with hematoxylin (Richard Allen, Richland, MI) and mounted on a no-aqueous medium (dibutilftalate xylol, DPX). Staining without antibody was performed routinely as a negative control. As positive controls, infiltrating lymphocytes were stained for bcl-2 and Bax.

\section{ER and PR immunohistochemistry}

The antigens were incubated with monoclonal antibody Novocastra NCL-L-ER-6F11 (1/25) against ERs and monoclonal antibody Novocastra NCL-L-PGR$312(1 / 25)$ against PR.

To identify antigen-antibody complexes, an immunoperoxidase method employing an avidin-biotin (StreptABC/HRP) peroxidase complex (TechMate 500 Plus, MSIP protocol, Vector Laboratories) was used. Peroxidase activity was demonstrated by incubation of the slides in DAB (Dako) followed by counterstaining with hematoxylin (Richard Allen) and mounted using a no-aqueous medium (DPX). Positive control was ER- and PR-positive breast cancer tissue, and specific staining was observed as nuclear browncolored granules. Negative control was ER- and PR-negative prostate cancer.

\section{Evaluation of immunohistochemical results}

All hemotoxylin and eosin (H\&E) and immunostained slides were independently reviewed by two observers (LC and EC). In cases of discrepancy, a consensus was always reached. Cytoplasm immunoreactivity specific for bcl-2 and Bax and nuclear immunoreactivity specific for ER and PR was expressed in terms of the percentage of cells exhibiting specific staining. In all 
cases, the intensity of staining was always stronger as more cells were positively stained. A negative staining was considered if less than $10 \%$ of the cells showed specific immunoreactivity, independent of the intensity of staining. Similarly, a positive staining was considered if $10 \%$ or more of the cells showed specific immunoreactivity. The distribution of the positive cells in the neoplastic epithelium was also recorded. In all cases, 500 cells were randomly counted.

\section{Statistical analysis}

Statistical analysis was computed at SSPS 10.0 for Windows (IL). For comparing the mean age, we used independent samples $t$-test. Chi-square and Fisher's exact test evaluated the differences in categorical data. The significance was adjusted by computing a binary logistic regression. A $P$ value of $<0.05$ was considered to reflect a significant difference.

\section{Results}

The results of HPV typing, the distribution of the three genotypes of p53 as either Arg and Pro homozygotes or Arg/Pro heterozygote, and the mean age of the patients in both MIC group and CIN III group are outlined in Tables 1, 2, and 3, respectively.

Immunostaining for ER and PR was specially localized to nuclear envelope and occasionally to the cytoplasm (Figs. 1 and 2) and all cases that stained, stained with lower intensity than control. Immunostaining for bcl-2 and Bax was always localized to the cell cytoplasm (Figs.3-5) and occasionally as a finely granular pattern.

In CIN III, the ER, PR, bcl-2, and Bax immunostaining usually involved all epithelial layers, but the expression of bcl-2 (Fig. 3) was more intense at the basal two-thirds of the neoplastic epithelium on both CIN III group and MIC group, and the Bax expression (Fig. 4) was stronger at the superficial two-thirds.

The immunohistochemical results for ER, PR, bcl-2, and Bax are outlined in Table 3. After adjustment, by multinomial logistic regression, only coexpression of

Table 1. HPV infection

\begin{tabular}{lcc}
\hline & MIC group $[n(\%)]$ & CIN III group $[n(\%)]$ \\
\hline HPV 16 & $26(89.7)$ & $17(68.0)$ \\
HPV 18 & $0(0.0)$ & $0(0.0)$ \\
Other HPV & $3(10.3)$ & $8(32.0)$ \\
Total & $29(100)$ & $25(100)$ \\
\hline
\end{tabular}

MIC group: CIN III at least $2 \mathrm{~mm}$ away from microinvasive complex from patients with the diagnosis of MIC; CIN III group: CIN III from patients with diagnosis of CIN III.
Table 2. p53 codon 72 polymorphism genotypes

\begin{tabular}{lcc}
\hline & MIC group $[n(\%)]$ & CIN III group $[n(\%)]$ \\
\hline Arg-Arg & $23(79.3)$ & $18(72.0)$ \\
Arg-Pro & $4(13.8)$ & $4(16.0)$ \\
Pro-Pro & $2(6.9)$ & $3(12.0)$ \\
Total & $29(100)$ & $25(100)$ \\
\hline
\end{tabular}

MIC group: CIN III at least $2 \mathrm{~mm}$ away from microinvasive complex from patients with the diagnosis of MIC; CIN III group: CIN III from patients with diagnosis of CIN III.

$\mathrm{ER}+\mathrm{PR}+\mathrm{bcl}-2$ remained as independent risk factors in defining low risk of progression for CIN III. We computed a sensitivity of $100 \%$ and a specificity of $64.4 \%$ for $\mathrm{ER}+\mathrm{PR}+\mathrm{bcl}-2$ as a marker for low risk of progression in CIN III.

For both the MIC group and the CIN III group, there was no statistically significant difference between $\mathrm{ER}+\mathrm{PR}+$ bcl-2-positive immunostaining and HPV type $(P=0.290)$ and p53 codon 72 polymorphism $(P=0.755)$.

\section{Discussion}

It has not been possible to predict the natural history of a particular CIN III, even after adequate treatment. Based on the reports of women with CIN III who inadvertently were not treated, we may assume that the progression rate may be high, and this is the reason for treating all women with $\mathrm{CIN} \mathrm{III}{ }^{(3,4)}$. After treatment, the best management policy in follow-up is not consensual. For the detection of persistent and recurrent high-grade CIN, colposcopy with directed biopsy is a good tool ${ }^{(48)}$, but is very expensive, time consuming, and limited to some medical centers. Cytology is not very sensitive ${ }^{(49,50)}$ and to compensate for its poor sensitivity, clinicians have traditionally used serial repeat cytology. HPV DNA testing for oncogenic HPV types seems comparable to repeated cytology $^{(51)}$. For treatment surveillance, the negative predictive value of HPV testing approaches $100 \%$, but the specificity is low, and this means that oncogenic HPV DNA may persist posttreatment without cytological or histological evidence of disease ${ }^{(52,53)}$.

This study was designed to find out a useful marker to identify a subset of CIN III with low risk of progression to invasive cancer. The immunohistochemical methodology is widely used worldwide. For this reason, we have chosen this technology to evaluate ER, PR, bcl-2, and Bax expression. Formalinfixed, paraffin-embedded tissue sections with microwave treatment was employed, which is an effective method to expose antigens and advantageous to 
Table 3. Age, HPV 16 and ER, PR, bcl-2, and Bax immunohistochemistry positive results

\begin{tabular}{lcccc}
\hline & MIC group (29 cases) & CIN III group (25 cases) & $P$ & Adjusted $P$ \\
\hline Mean age (years) & $41.79 \pm 8.89$ & $36.04 \pm 10.67$ & 0.035 & 0.267 \\
ER positive $[n(\%)]$ & $10(34.5)$ & $11(44.0)$ & 0.579 & 0.094 \\
PR positive $[n(\%)]$ & $8(27.6)$ & $13(52.0)$ & 1.000 & - \\
Bcl-2 positive & 16 & 13 & 0.493 & - \\
Bax positive & 27 & 25 & 0.023 \\
ER + PR positive & $3(10.3)$ & $10(40.0)$ & 1.000 \\
Bcl-2+ Bax positive & $14(48.3)$ & $13(52.0)$ & 0.0004 & - \\
ER + PR + Bcl-2 positive & $0(0.0)$ & $9(36.0)$ & 0.023 & - \\
ER + PR + Bax positive & $3(10.3)$ & $10(40.0)$ & 0.001 \\
\hline
\end{tabular}

MIC group: CIN III at least $2 \mathrm{~mm}$ away from microinvasive complex from patients with the diagnosis of MIC; CIN III group: CIN III from patients with diagnosis of CIN III. ER, estrogen receptor; PR, progesterone receptor.

observe a wider area of tissue sections ${ }^{(54)}$. The HPV typing and p53 Arg/Pro polymorphism were also studied, as they could be possible confounding variables.

We evaluated the CIN III in 29 patients with MIC, and 25 patients with CIN III were selected as a control group. Probably, this control group belongs to a subset of CIN III with low risk for progression, because all patients had at least 30 months of follow-up without progression or recurrence and no abnormal Pap smear during the follow-up period.

Our results showed that women with MIC were about 5 years older than patients with CIN III group, which is in accordance with a Costa Rica study that

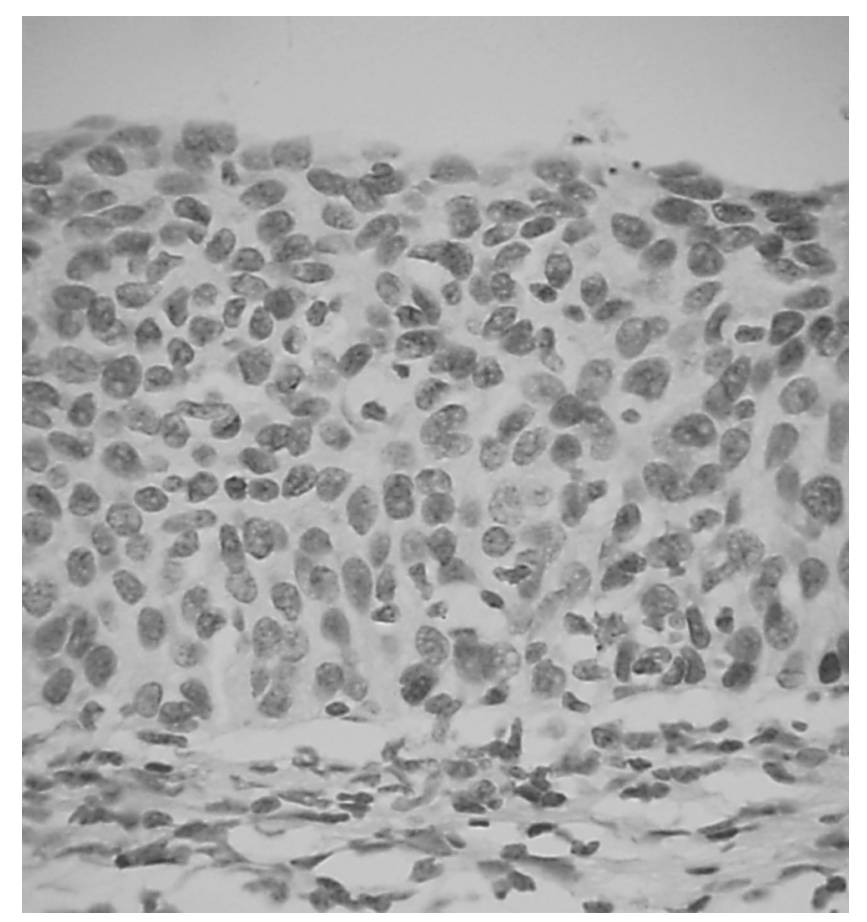

Fig. 1. This figure shows a CIN III with nuclear staining positive for ER $(\times 40)$. suggests that CIN III progresses to subclinical cancer in about 5 years and that symptomatic cancer arises 4 to 5 years later ${ }^{(55)}$.

We reported a high prevalence of HPV 16 infection in both the studied groups, in agreement with a worldwide study conducted by Bosh et al. ${ }^{(56)}$ who found a high prevalence of HPV 16 in cervical cancer in Europe. Identical study on a Portuguese population detected HPV 16 DNA sequences by PCR in $83.3 \%$ of squamous cell cervical cancers ${ }^{(57)}$.

There are no published studies on p53 polymorphism in Portuguese population, but the frequency of homozygous arginine p53 polymorphism has been

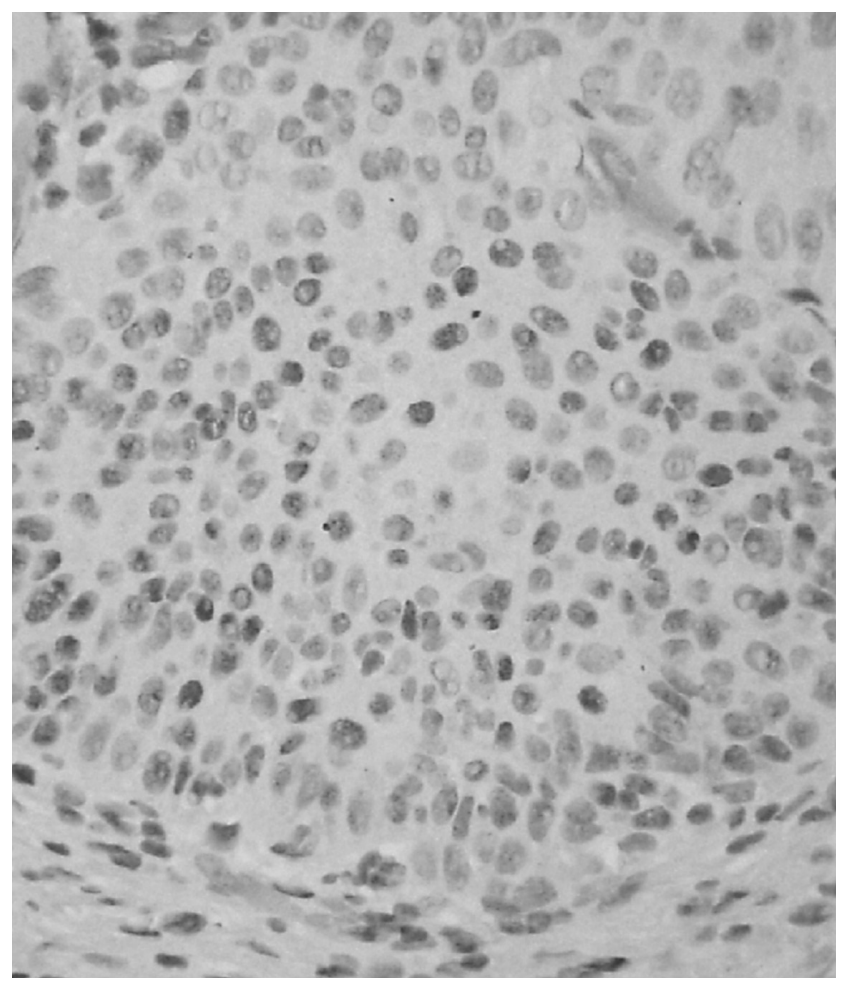

Fig. 2. This figure shows a CIN III with nuclear staining positive for PR $(\times 40)$.

(C) 2004 IGCS, International Journal of Gynecological Cancer 14, 911-920 


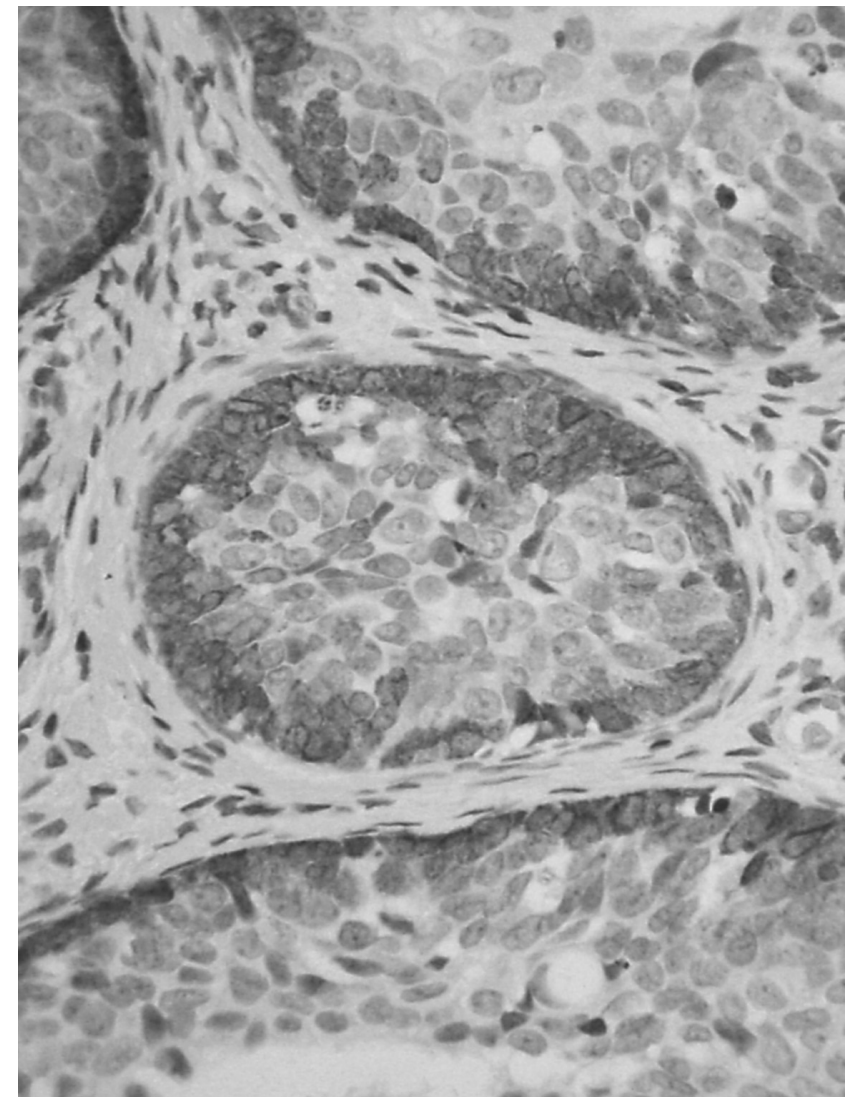

Fig. 3. This figure shows a CIN III with cytoplasm basal staining positive for bcl-2 $(\times 40)$.

reported as higher as $50 \%$ in many Caucasian groups ${ }^{(19,20,58,59)}$ in accordance with the high frequency detected in our samples. We found that p53 polymorphism has no value in predicting progression of CIN III which is in agreement with previous studies reporting that p53 polymorphism has no prognostic significance in cervical cancer ${ }^{(60,61)}$. In the present study, the p53 polymorphism was not related to HPV type, as reported by others ${ }^{(60-62)}$.

Clinical evidence that estrogens and progesterone may have a carcinogenic effect in HPV-infected cervix was recently reported in two multicentric case-control studies $^{(63,64)}$. Our ER- and PR-positive results are similar to previous studies relying on ER and PR detection in cervical cancer ${ }^{(39,65-69)}$. However, wide variation exists between ER and PR reports on cervical cancer probably due to the differences in the methods employed, sample preparation, and different cut-off values for positive results. We found a significantly higher positive coexpression of $\mathrm{ER}$ and $\mathrm{PR}$ in the CIN III group than in CIN III of the MIC group. As induction of $\mathrm{PR}$ is one of the best-recognized responses to estrogen in target tissues ${ }^{(70,71)}$, we can hypothesize that in the MIC group, most of ER may

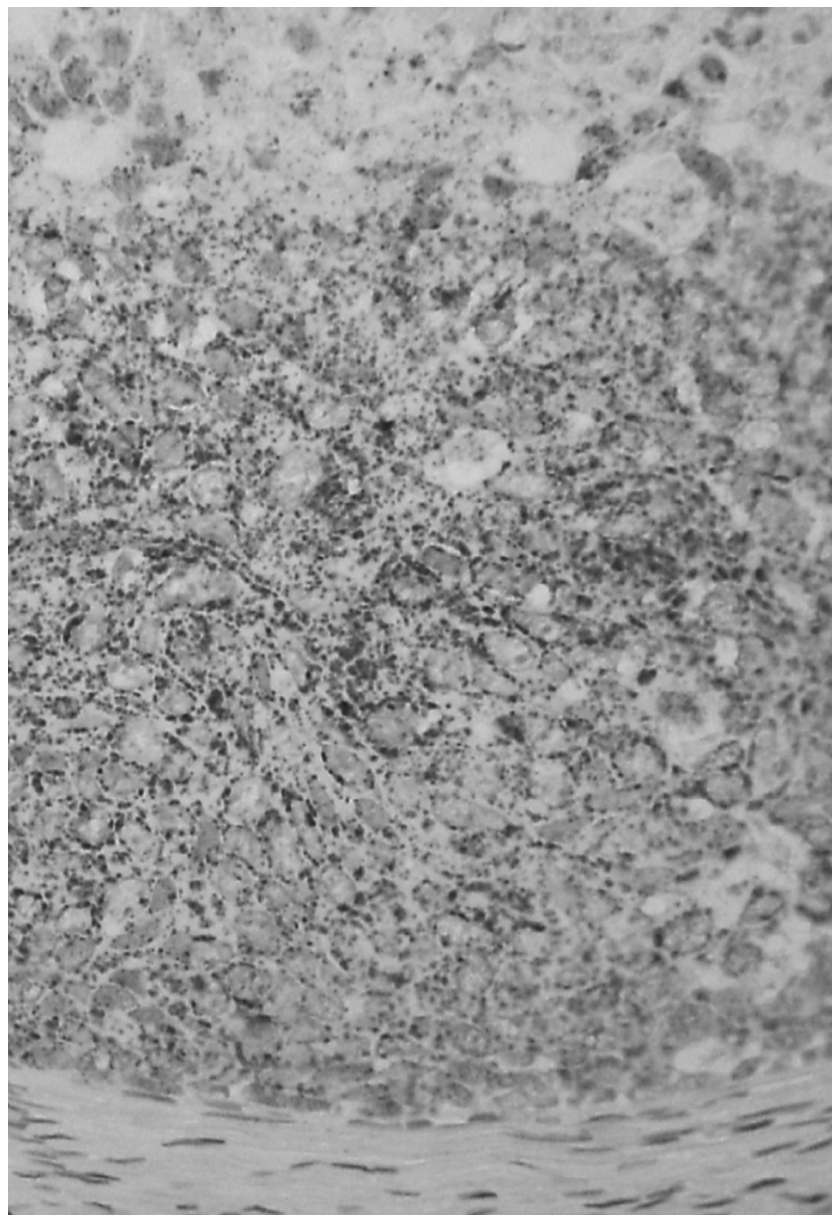

Fig. 4. This figure shows a CIN III with cytoplasm diffuse staining positive for bcl-2 $(\times 40)$.

have no or reduced functional activity. The finding that in all cases in the MIC group with coexpression of $\mathrm{ER}$ and PR, the ER staining was stronger and

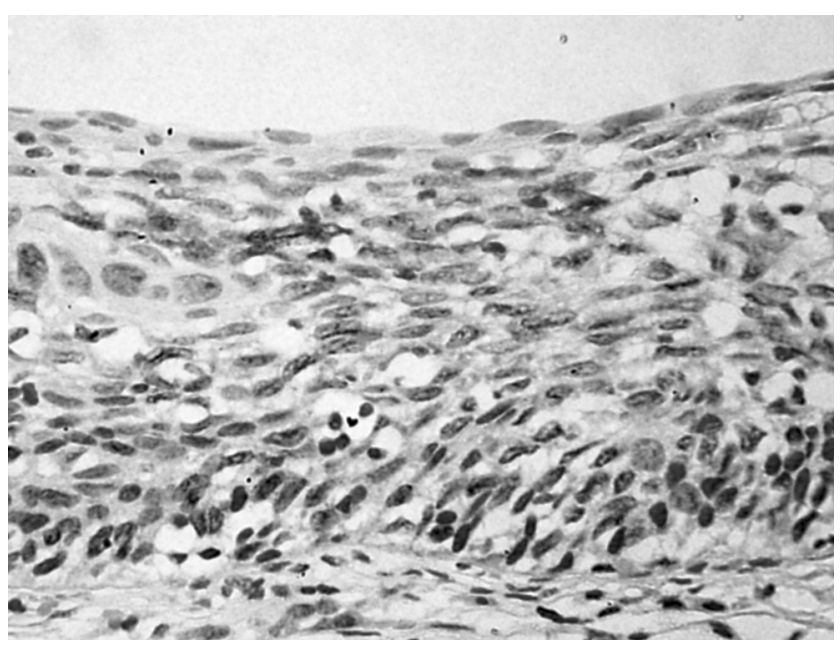

Fig. 5. This figure shows a CIN III with cytoplasm granular staining positive for $\operatorname{Bax}(\times 40)$. 
expressed in more cells than PR staining, which is not true for CIN III group, supports this idea. Moreover, coexpression of ER, PR, and bcl-2 was observed in CIN III group but not in MIC group, which agrees with previous studies suggesting an estrogen-dependent upregulation of bcl- $2^{(72,73)}$.

Several studies have shown that HPV gene expression can be increased in response to both estrogen and progesterone stimulation ${ }^{(41-43)}$. Webster et al. ${ }^{(74)}$ reported that estrogen and progesterone increase the level of apoptosis induced by HPV 16 E2 and E7 proteins, and they suggest that in the presence of E2, these hormones may be protective against cervical cancer via their upregulation of apoptotic cell death.

Apoptosis is regulated by a balanced interaction of genes, among which bcl-2 and Bax are the most important ${ }^{(75-77)}$. The ratio between Bax and bcl-2 gene expression determines the susceptibility of the cell to apoptosis ${ }^{(78-80)}$. In cells with Bax overexpression, the susceptibility to apoptosis is enhanced and, on the contrary, an excess of bcl-2 protein appears to be associated with carcinogenesis ${ }^{(80)}$. In the present study, both in MIC and CIN III groups, the expression of Bax was always stronger and present in more cells than bcl-2 staining, suggesting a driving stimulus toward apoptosis. However, Bax immunostaining has shown no significant differences in both CIN III and cervical cancer ${ }^{(81-83)}$, suggesting that Bax expression is not always required for induction of apoptosis in cervical neoplastic cells ${ }^{(84)}$.

Some authors found a stronger bcl-2 immunostaining in CIN III than in cervical cancer, supporting the hypothesis that the loss of bcl-2 expression occurs during the evolution of the malignant phenotype ${ }^{(81,82,85-87)}$. Others did not find this association ${ }^{(83)}$. These studies have reported that the progression of $\mathrm{CIN}$ is accompanied by increasing bcl-2 protein overexpression and suggest that the progression of CIN is reflected by the bcl-2 expression levels. In CIN III, bcl-2 tends to extend into the higher layers of the epithelium, preventing apoptosis and facilitating proliferation. It is difficult to explain why bcl-2 expression is lost in invasive cervical cancer, but we may speculate that, after neoplastic transformation, apoptosis may not be under the normal control mechanisms. In our study, the pattern of bcl-2 staining in studied CIN III of MIC group and CIN III group was similar, probably because both the groups of CIN III were closest on apoptosis control than with low-grade CIN.

In conclusion, our study suggests that positive immunohistochemical coexpression of ER, PR, and bcl-2 may be a useful tool in identifying a subset of patients with CIN III that have a low risk for cancer progression, independent of the patient's age and HPV status. Further studies performed in different populations and in different laboratories must validate these data.

\section{Acknowledgments}

We are grateful to Portuguese Cancer Institute that supported partially this work. We thank Prof. Vitor Rodrigues, Epidemiologist of Coimbra Medicine School, the statistical counseling.

\section{References}

1 Parkin DM, Pisani P, Ferlay J. Estimates of the worldwide incidence of 25 major cancers in 1990. Int J Cancer 1990;80:827-41.

2 Richard RM. Cervical intraepithelial neoplasia. In: Sonners SC, ed. Pathology Annual. New York: Appleton, 1973: 301-28.

3 MacIndoe WA, MacLean MR, Jones RW. The invasive potential of carcinoma in-situ of the cervix. Obstet Gynecol 1984;64:451-8.

4 Ostor AG. Natural history of cervical intraepithelial neoplasia: a critical review. Int J Gynecol Pathol 1993;12: 186-92.

5 Herbert A, Smith JA. Cervical intraepithelial neoplasia grade III (CINIII) and invasive cervical carcinoma: the yawning gap revisited and the treatment of risk. Cytopathology 1999;10:161-70.

6 Walboomers JMM, Jacobs MV, Manos MM et al. Human papillomavirus is a necessary cause of invasive cervical cancer worldwide. J Pathol 1999;189:12-9.

7 Munoz N, Bosh FX, de Sanjose S et al. The causal link between human papillomavirus and invasive cancer: a population-based study in Colombia and Spain. Int J Cancer 1992;52:743-9.

8 Bosh FX, Munoz N, de Sanjose S et al. Human papillomavirus and cervical intraepithelial neoplasia grade III/ carcinoma in-situ: a case control study in Spain and Colombia. Cancer Epidemiol Biomarkers Prev 1993;2: 415-22.

9 Eluf-Neto J, Booth M, Munoz N et al. Human papillomavirus and invasive cervical cancer in Brazil. Br J Cancer 1994;69:114-9.

10 Becker TM, Wheeler CM, McGoug NS et al. Sexually transmitted diseases and other risk factors for cervical dysplasia among southwestern Hispanic and nonHispanic white women. JAMA 1994;271:1181-8.

11 Liaw KL, Hsing AW, Chen CJ et al. Human papillomavirus and cervical neoplasia: a case-control study in Taiwan. Int J Cancer 1995;62:565-71.

12 Park TW, Fujiwara H, Write TC. Molecular biology of cervical cancer and its precursors. Cancer 1995;76: 1902-13.

13 Klaes R, Woerner SM, Ridder R et al. Detection of highrisk cervical intraepithelial neoplasia and cervical cancer by amplification of transcripts derived from integrated papillomavirus oncogenes. Cancer Res 1999;59:6132-6. 
14 Scheffner M, Huibregtse JM, Viestra RD et al. The HPV16 E6 and E6-AP complex functions as a ubiquitinprotein ligase in the ubiquitination of p53. Cell 1993;75: 495-505.

15 Huibregtse JM, Scheffner M, Howley PM. Cloning and expression of the cDNA for E6-AP, a protein that mediates the interaction of the human papillomavirus E6 oncoprotein with p53. Mol Cell Biol 1993;13:775-84.

16 Fujita M, Inoue M, Tanizawa $\mathrm{O}$ et al. Alterations of the p53 gene in human primary cervical carcinoma with and without papillomavirus infection. Cancer Res 1992;52: 5323-8.

17 Park DJ, Wilczinski SP, Paquette RL et al. P53 mutations in HPV-negative cervical carcinoma. Oncogene 1994;9: 205-10.

18 Birgander R, Sjalander A, Rannug A et al. p53 polymorphisms and haplotypes in lung cancer. Carcinogenesis 1995;16:2233-6.

19 Storey A, Thomas M, Kalita A et al. Role of a p53 polymorphism in the development of human papillomavirus-associated cancer. Nature 1998;393:229-34.

20 Josefsson M, Magnusson PKE, Ponte $\mathrm{N}$ et al. P53 polymorphism and risk for cervical cancer. Nature 1998;359:31.

21 Arbel-Alon S, Menczer J, Feldman N et al. Codon 72 polymorphism of p53 in Israeli Jewish cervical cancer patients and healthy women. Int J Gynecol Cancer 2002;12:741-4.

22 Boyer SN, Waser DE, Band V. E7 protein of human papilloma virus-16 induces degradation of retinoblastoma protein through the ubiquitin-proteasome pathway. Cancer Res 1996;56:4620-4.

23 Field SJ, Tsai FY, Kuo F et al. E2F-1 functions in mice to promote apoptosis and suppress proliferation. Cell 1996;85:549-61.

$24 \mathrm{Wu}$ X, Levine AJ. P53 and E2F-1 cooperate to mediate apoptosis. Proc Natl Acad Sci USA 1994;91:3602-6.

25 Crawford RAF, Caldwell C, Iles RK et al. Prognostic significance of the bcl-2 apoptotic family of proteins in primary and recurrent cervical cancer. Br J Cancer 1998; 78:210-4.

26 Tjalma J, Weyler G, Goovaerts C et al. Prognostic value of bcl-2 expression in patients with operable carcinoma of uterine cervix. J Clin Pathol 1997;50:113-7.

27 Baretton GB, Diebold J, Christoforis G et al. Apoptosis and immunohistochemical bcl-2 expression in colorectal adenomas and adenocarcinomas. Cancer 1996;77:255-64.

28 Hellemans P, van Dam PA, Weyler J et al. Prognostic value of bcl-2 expression in invasive breast cancer. $\mathrm{Br} J$ Cancer 1995;72:354-60.

29 Kurniven K, Syrjanen K, Syrjanen S. p53 and bcl-2 proteins as prognostic markers in human papillomavirusassociated cervical lesions. J Clin Oncol 1996;14:2120-30.

30 Wheeler JA, Stephens LC, Tornos C et al. ASTRO research fellowship: apoptosis as a predictor of tumor response to radiation in stage IB cervical carcinoma. Int J Radiat Oncol Biol Phys 1995;32:1487-93.

31 Ohno T, Nakano T, Niibe Y et al. Bax protein expression correlates with radiation-induced apoptosis in radiation therapy for cervical carcinoma. Cancer 1998;83:103-10.

32 Harima Y, Harima K, Shikata N et al. Bax and Bcl-2 expressions predict response to radiotherapy in human cervical cancer. I Cancer Res Clin Oncol 1998;124: 503-10.

33 Harima Y, Nagata K, Harima K et al. Bax and Bcl-2 protein expression following radiation plus thermoradiotherapy in stage IIIB cervical carcinoma. Cancer 2000;88:132-8.

34 Autier P, Coibion M, Huet F et al. Transformation zone location and intraepithelial neoplasia of the cervix uteri. Br J Cancer 1996;74:488-90.

35 Clark GM, MacGuide WL, Hubay CA et al. Progesterone receptors as a prognostic factor in stage II breast cancer. N Engl J Med 1983;309:1343-7.

36 Fukuda K, Mori M, Uchiyama M et al. Prognostic significance of progesterone receptor immunohistochemistry in endometrial carcinoma. Gynecol Oncol 1998;69: 220-5.

37 Bizzi A, Codegoni AM, Landoni F et al. Steroid receptors in epithelial ovarian carcinoma: relations to clinical parameters and survival. Cancer Res 1988;48:6222-6.

38 Suzuki Y, Nakano T, Arai Tet al. Progesterone receptor is a favorable prognostic factor of radiation therapy for adenocarcinoma of uterine cervix. Int J Radiat Oncol Biol Phys 2000;47:1229-34.

39 Kim JW, Sung HR, Kim DK et al. Estrogen and progesterone receptor assay in carcinoma of the cervix with monoclonal antibodies. Gynecol Oncol 1992;47:306-10.

40 Webster K, Taylor A, Gaston K. Oestrogen and progesterone increase the level of apoptosis induced by human papillomavirus type 16, E2 and E7 proteins. J Gen Virol 2001;82:201-13.

41 Yuan F, Auborn K, James C. Altered growth and viral gene expression in human papillomavirus type 16-containing cancer cell lines treated with progesterone. Cancer Invest 1999;17:19-29.

42 Yuan F, Chen D, Liu K et al. Anti-estrogenic activities of indole-3-carbinol in cervical cells: implication for prevention of cervical cancer. Anticancer Res 1999;19: 1673-80.

$43 \mathrm{Kim}$ CJ, Um SJ, Kim TY et al. Regulation of the cell growth and HPV genes by exogenous estrogen in cervical cancer cells. Int J Gynecol Cancer 2000;10:157-64.

44 Ting Y, Manos MM. Detection and typing of genital human papillomavirus, in PCR protocols: a guide to methods and applications. New York: Academic Press, 1990: 356-67.

45 Kleter B, Doorn L, Schegget J et al. Novel short-fragment PCR assay for highly sensitive broad spectrum detection of anogenital human papillomavirus. Am J Pathol 1998;153:1731-9.

46 Shibata D, Arnheim N, Martin W. Detection of human papillomavirus in paraffin-embedded tissue using the polymerase chain reaction. J Exp Med 1988;167:225-30.

47 Tam K, Chow V. Diagnostic sensitivity of polymerase chain reaction and southern blot hybridization for the detection of human papillomavirus DNA in biopsy specimens from cervical lesions. Am I Clin Pathol 1991;95:638-46.

48 Husseinzadeh N, Shbaro I, Wesseler T. Predictive value of cone margins and post-cone endocervical curettage with residual disease in subsequent hysterectomy. Gynecol Oncol 1989;33:198-200.

49 Wright TC, Lorincz AT, Ferris DG et al. Reflex HPV testing in women with abnormal Papanicolaou smears. Am J Obstet Gynecol 1998;178:962-6. 
50 Manos MM, Kinney WK, Hurley LB et al. Identifying women with cervical neoplasia using human papillomavirus DNA testing for equivocal Papanicolaou results. JAMA 1999;281:1605-10.

51 Soloman D, Schiffman M, Tarone R. Comparison of three management strategies for patients with atypical squamous cells of undetermined significance. Baseline results from a randomized study. J Natl Cancer Inst 2001;93:293-9.

52 Lin CT, Tseng CJ, Lai CH et al. Value of human papillomavirus deoxyribonucleic acid testing after conization in the prediction of residual disease in the subsequent hysterectomy specimen. Am J Obstet Gynecol 2001;184:940-5.

53 Jain S, Tseng CJ, Horng SG et al. Negative predictive value of human papillomavirus test following conization of the cervix uteri. Gynecol Oncol 2001;28:177-80.

54 Taylor CR, Shi SR, Chaiwun B et al. Strategies for improving the immunohistochemical staining of various intranuclear prognostic markers in formalin-paraffin sections: androgen receptor, estrogen receptor, progesterone receptor, p53 protein, proliferating cell nuclear antigen and Ki-67 antigen revealed by antigen retrieval techniques. Hum Pathol 1994;25:263-70.

55 Herrero R, Hildesheim A, Bratti A et al. Populationbased study of human papillomavirus infection and cervical neoplasia in rural Costa Rica. J Natl Cancer Inst 2000;92:464-74.

56 Bosh FX, Manos MM, Muñoz N et al. Prevalence of human papillomavirus in cervical cancer: a worldwide perspective. International biological study on cervical cancer (IBSCC) Study Group. J Natl Cancer Inst 1995; 87:796-802.

57 Serra H, Pista A, Figueiredo P et al. Cervix uteri lesions and human papillomavirus infection (HPV): detection and characterization of DNA/HPV using PCR (polymerase chain reaction). Acta Med Port 2000;13:181-92.

58 Tachezy R, Mikyscova I, Salakova M et al. Correlation between human papillomavirus-associated cervical cancer and p53 codon 72 arginine/proline polymorphism. Hum Genet 1999;105:564-6.

59 Giannoudis A, Graham DA, Southern S et al. p53 codon 72 ARG/PROL polymorphism is not related to HPV type or lesion grade in low and high-grade squamous intra-epithelial lesions and invasive squamous carcinoma of the cervix. Int J Cancer 1999;83:66-9.

60 Nishikawa A, Fujimoto T, Akutagawa N et al. p53 polymorphism (codon-72) has no correlation with the development and the clinical features of cervical cancer. Int $J$ Gynecol Cancer 2000;10:402-7.

61 Ngan HY, Liu VW, Liu SS et al. Homozygous arginine at codon 72 of p53 has no prognostic significance in cervical cancer. Tumour Biol 2000;21:135-8.

62 Dokianakis DN, Spandidos DA. P53 codon 72 polymorphism as a risk factor in the development of HPVassociated cervical cancer. Mol Cell Biol Res Commun 2000;3:111-4.

63 Moreno V, Bosch FX, Munoz N et al. Effect of oral contraceptives on risk of cervical cancer in women with human papillomavirus infection. The IARC multicentric casecontrol study. Lancet 2002;359:1085-92.

64 Munoz N, Franceschi S, Bosetti C et al. Role of parity and human papillomavirus in cervical cancer. IARC multicentric case-control study. Lancet 2002;359:1093-101.
65 Soutter WP, Pegoraro RJ, Thompson RW, Naidoo DV, Joubert SM, Philpott RH. Nuclear and progesterone estrogen receptors in squamous carcinoma of the cervix. Br J Cancer 1981;44:154-9.

66 Hunter RE, Longcope C, Keough P. Steroid hormone receptors in carcinoma of the cervix. Cancer 1987;60: 392-6.

67 Hahnel B, Martin JD, Master AM. Estrogen receptor and blood hormone levels in cervical carcinoma and others gynaecological carcinomas. Gynecol Oncol 1979;8:226-33.

68 Kanai M, Shiozawa T, Xin L et al. Immunohistochemical detection of sex steroid receptors, cyclins, and cyclindependent kinases in normal and neoplastic squamous epithelia of the uterine cervix. Cancer 1998;82:1709-19.

69 Park CS, Joo IS, Song SY et al. An immunohistochemical analysis of heat shock protein 70, 53, and estrogen receptor status in carcinoma of uterine cervix. Gynecol Oncol 1999;74:53-60.

70 Namer M, Lalanne C, Baulieu EE. Increase of progesterone receptor by tamoxifen as a hormonal challenge test in breast cancer. Cancer Res 1980;40:1750-2.

71 Iacobelli S, Scambia B, Atlante G et al. Effect of tamoxifen on steroid hormone receptors and creatine kinase activity in human endometrial carcinoma. Eur J Cancer Clin Oncol 1986;22:105-10.

72 Kandouzi M, Siro Machkova M, Jacob B et al. Antagonism between estradiol and progestin on bcl-2 expression in breast cancer cells. Int J Cancer 1996;68:120-5.

73 Tao X, Tilly KI, Maravel DV et al. Differential expression of members of the bcl-2 gene family in proliferative and secretory human endometrium: glandular epithelial cell apoptosis is associated with increased expression of bax. J Clin Endocrinol Metab 1997;82:2738-46.

74 Webster K, Taylor A, Gaston K. Oestrogen and progesterone increase the levels of apoptosis induced by human papillomavirus type 16, E2 e E7 proteins. J Gen Virol 2001;82:201-13.

75 Miyashita T, Krajewski S, Krajeweska $\mathrm{M}$ et al. Tumor suppressor p53 is a regulator of $\mathrm{Bcl}-2$ and $\mathrm{Bax}$ gene expression in vitro and in vivo. Oncogene 1994;9: 1799-805.

76 Kapranos N, Karaiosifidi H, Valavanis C et al. Prognostic significance of apoptosis related proteins bcl-2 and Bax in node-negative breast cancer patients. Anticancer Res 1997; 17:2499-505.

77 Staunton M, Gaffney E. Apoptosis. Arch Pathol Lab Med 1998;122:310-9.

78 Guinee D, Brambilla E, Fleming M et al. The potential role of bax and bcl-2 expression in diffuse alveolar damage. Am J Pathol 1997;151:999-1007.

79 Kapucuoglu N, Losi L, Eusebi V. Immunohistochemical localization of Bcl-2 and Bax proteins in situ and invasive duct breast carcinomas. Virchows Arch 1997;430: 125-30.

80 Saitoh Y, Yaginuma Y, Ishikawa M. Analysis of Bcl-2, Bax and Survivin genes in uterine cancer. Int J Oncol 1999; 15:137-41.

81 Saegusa M, Takano Y, Hashimura M et al. The possible role pf bcl-2 expression in the progression of tumors of the uterine cervix. Cancer 1995;76:2297-303.

82 Aletra C, Ravazoula P, Scopa C et al. Expression of bcl-2 and bax in cervical intraepithelial neoplasia and invasive 
squamous cell carcinoma of the uterine cervix. Eur J Gynaecol Oncol 2000;21:494-8.

83 Nair P, Nair MK, Jayaprakash PG et al. Decreased programmed cell death in the uterine cervix associated with high-risk human papillomavirus infection. Pathol Oncol Res 1999;5:95-103.

84 Butz K, Geisen C, Ullman A et al. Cellular response of HPV-positive cancer cells to genotoxic anti-cancer agents: repression of E6/E7-oncogene expression and induction of apoptosis. Int J Cancer 1996;68:506-13.

85 Harmsel BT, Smedts F, Kuijpers J et al. Bcl-2 immunoreactivity increases with severity of CIN: A study of normal cervical epithelia, CIN, and cervical carcinoma. J Pathol 1996;179:26-30.

86 Harmsel BT, Kuijpers J, Smeths F et al. Progressing imbalance between proliferation and apoptosis with increasing severity of cervical intraepithelial neoplasia. Int J Gynecol Pathol 1997;16:205-11.

87 Tjalma W, De Guyper E, Weyler J et al. Expression of bcl-2 in invasive and in situ carcinoma of the cervix. Am J Obstet Gynecol 1998;178:113-7.

Accepted for publication November 19, 2003 
Copyright of International Journal of Gynecological Cancer is the property of Blackwell Publishing Limited and its content may not be copied or emailed to multiple sites or posted to a listserv without the copyright holder's express written permission. However, users may print, download, or email articles for individual use. 